\title{
Protection of rainbow trout from infectious hematopoietic necrosis (IHN) by injection of infectious pancreatic necrosis virus (IPNV) or Poly(I:C)
}

\author{
Hyoung Jun Kim ${ }^{1}$, Norihisa Oseko ${ }^{2}$, Toyohiko Nishizawa ${ }^{1, *}$, Mamoru Yoshimizu ${ }^{1}$ \\ ${ }^{1}$ Faculty of Fisheries Sciences, Hokkaido University, Hakodate, 041-0811, Japan \\ ${ }^{2}$ National Research Institute of Aquaculture, Fisheries Research Agency, Sapporo, 062-0992, Japan
}

\begin{abstract}
It was recently reported that prophylaxis against infectious hematopoietic necrosis virus (IHNV) in fish was induced by pre-exposure to the infectious pancreatic necrosis virus (IPNV). Here the establishment of IHNV immunity in rainbow trout Oncorhynchus mykiss was investigated by IHNV challenge following non-lethal pre-infection with IPNV. Also, synthetic double-stranded RNA polyinosinic polycytidylic acid, Poly(I:C), an inducer for interferon (IFN), was evaluated as a substitute for IPNV induction of the non-specific antiviral state and subsequent IHNV-specific immunity in fish. Rainbow trout pre-infected with IPNV were protected from IHNV challenge $7 \mathrm{~d}$ later (relative percentage survival, RPS: $68.8 \%$ ), and IHNV-specific antibodies were detected in sera from the survivors. Moreover, these surviving fish showed 91.6\% RPS when re-challenged with IHNV $28 \mathrm{~d}$ after the primary IHNV challenge. Thus, fish appear to acquire IHNV-specific immunity through the IHNV challenge following pre-injection with IPNV. Fish pre-injected with Poly(I:C) were also highly protected from IHNV challenge 2 d later (RPS: $95.2 \%$ ), and IHNV-specific antibodies were also detected amongst survivors. The survivors showed a $100 \%$ survival rate following re-challenge with IHNV both 21 and $49 \mathrm{~d}$ after the primary IHNV challenge. Thus, IHNV immunity in rainbow trout is induced by challenge with live IHNV following pre-injection with either IPNV or Poly(I:C). The use of Poly(I:C) to induce an anti-viral state protecting rainbow trout from an otherwise lethal vaccination dose of IHNV may have application to a wider range of fish species and fish pathogenic viruses.
\end{abstract}

KEY WORDS: Immunization · Infectious hematopoietic necrosis virus · IHNV · Poly(I:C) · Interferon · Antiviral state $\cdot$ Dual infection $\cdot$ Vaccine

Resale or republication not permitted without written consent of the publisher

\section{INTRODUCTION}

Infectious hematopoietic necrosis (IHN) is one of the most serious diseases of salmonids. Because outbreaks of IHN can result in losses of over $80 \%$, depending on the species and size of fish, virus strain and environmental conditions (Wolf 1988). The causative agent, IHN virus (IHNV), is a member of the genus Novirhabdovirus in the family Rhabdoviridae (Kurath et al. 1985, Tordo et al. 2005). IHNV is currently enzootic throughout the Pacific Northwest of North America, but was spread by movement of IHNV-contaminated fish or fish eggs to Asian and European countries in the 1960s to 1970s (Kimura \& Yoshimizu 1991, Winton 1991, Nishizawa et al. 2006a). The imported IHNV has evolved rapidly in the rainbow trout Oncorhynchus mykiss farm environment in Japan (Nishizawa et al. 2006a), and some of the Japanese isolates of IHNV have spread to Korea (Kim et al. 2007b). In recent years, serious losses due to IHN have been observed in adult and market size rainbow trout, although IHNV tends to 
be more pathogenic in juveniles. The evolutionary divergence of IHNV influences its pathogenicity, but this has not been elucidated scientifically (Nishizawa et al. 2006a).

In seed production facilities for salmonids, stable production of specific-pathogen-free (SPF) fish has been accomplished by measures for the prevention of IHNV transmission, such as disinfection of eggs with iodine, and sterilization of rearing water and facilities. Furthermore, maintenance of SPF-spawners monitored by antibody detection (ELISA) is also important and helpful to prevent vertical transmission of IHNV (Yoshimizu 1996, 2003). However, it is still difficult to prevent horizontal transmission of IHNV through water flow in rainbow trout farms. Therefore, development of an IHNV vaccine is essential, and several kinds of efficacious IHNV vaccines have been developed, e.g. killed or attenuated vaccines (Winton 1997, Biering et al. 2005), recombinant vaccines with IHNV G protein (Xu et al. 1991, Cain et al. 1999) and DNA vaccines with IHNV G gene (Anderson et al. 1996, Kim et al. 2000, Lorenzen et al. 2002).

Protection of salmonids from IHNV, viral hemorrhagic septicemia virus (VHSV) and/or infectious salmon anemia virus (ISAV) can be induced by preexposure of fish to infectious pancreatic necrosis virus (IPNV), aquareovirus or picornavirus (de Kinkelin et al. 1992, Hedrick et al. 1994, LaPatra et al. 1995, Johansen \& Sommer 2001, Byrne et al. 2008). Furthermore, in marine fishes, primary infection of Japanese flounder and sevenband grouper Epinephelus septemfasciatus by aquabirnavirus confers protection from other pathogenic viruses, such as VHSV and fish nodavirus (Pakingking et al. 2003, 2005). The protection from the secondary infection of virus was due to an interferon (IFN) activity induced in the fish by the primary infection (Pakingking et al. 2004, Das et al. 2007, McBeath et al. 2007). Polyinosinic polycytidylic acid (Poly(I:C)), a synthetic double-stranded RNA, is commonly used as an IFN inducer in many different animals. IFN is induced in rainbow trout by Poly(I:C) injection, causing the injected fish to develop an antiviral state (Eaton 1990, Trobridge et al. 1997, Purcell et al. 2004).

In the present study, establishment of IHNV immunity in rainbow trout Oncorhynchus mykiss that survived IHNV infection following pre-infection with nonlethal IPNV was investigated by re-challenge with IHNV. Moreover, Poly(I:C) was evaluated for use as a substitute for non-lethal IPNV for the induction of an antiviral state in fish. It was demonstrated that injection with IPNV or Poly(I:C) allows the fish to survive the subsequent IHNV infection, which then stimulates specific immunity against IHNV.

\section{MATERIALS AND METHODS}

Viruses. IHNV RtNag96 and IPNV RtNag00 were used for experimental infection of rainbow trout, while IHNV RtNag96 and VHSV Obama25 were used as viral antigens for ELISA antibody detection. IHNV RtNag96 was isolated from IHN-affected rainbow trout in Nagano Prefecture, Japan in 1996, and classified into the genogroup JRt (Nishizawa et al. 2006a). IPNV RtNag00 was obtained from apparently healthy rainbow trout in Nagano Prefecture in 2000, and classified into the Genogroup I of the genus Aquabirnavirus (Nishizawa et al. 2005). IPNV RtNag00 is not, or only seldom lethal to rainbow trout. No mortality was observed in rainbow trout injected with this isolate at a $10^{6.3} 50 \%$ tissue culture infectious dose $\left(\mathrm{TCID}_{50}\right) \mathrm{fish}^{-1}$ using a standard challenge system (data not shown), although the mechanism is not clear. VHSV Obama25 was isolated from free-living Japanese flounder Paralichthys olivaceus caught in the Obama coastal area of the Wakasa Bay, Japan, in 1999 (Takano et al. 2000, 2001), and classified into the Genogroup IV of VHSV (Nishizawa et al. 2002, 2006b).

The viruses were propagated in epithelioma papulosum cyprini (EPC) cells, which were maintained at $15^{\circ} \mathrm{C}$ with Eagle's minimum essential medium (MEM, Gibco) supplemented with $10 \%$ fetal bovine serum, $100 \mathrm{IU} \mathrm{ml}^{-1}$ penicillin $\mathrm{G}$ and $100 \mathrm{\mu g} \mathrm{ml}^{-1}$ streptomycine sulfate $\left(\mathrm{MEM}_{10}\right)$. Titration of viral infectivity was performed using 96-well microplates, seeded with EPC cells. After culture at $15^{\circ} \mathrm{C}$ for $14 \mathrm{~d}$, cytopathic effect (CPE) was evaluated to determine the $\mathrm{TCID}_{50}$.

IHNV challenge for fish pre-infected with IPNV. $\mathrm{SPF}$ rainbow trout juveniles of $1.3 \pm 0.2 \mathrm{~g}$ body weight were kindly contributed by Mr. K. Kohara in Nagano Prefectural Fisheries Experimental Station, in Japan. The SPF nature of the fish was cleared not only for IPNV and IHNV but also for other rainbow trout viruses by culture-isolation test using RTG-2, EPC and CHSE-214 cell lines. The fish were reared in $10 \mathrm{l}$ tanks at 10 to $11^{\circ} \mathrm{C}$ with 24 exchanges per day, and fed a commercial dry-pellet diet at approximately 1 to $2 \%$ of body weight $\mathrm{d}^{-1}$ during the following experiments. The experimental design scheme of IPNV-injection and IHNV challenges is shown in Fig. 1. After 2 wk for acclimation, IPNV at a dose of $10^{6.3}$ TCID $_{50} 50 \mu^{-1}$ fish $^{-1}$ or the same volume of $\mathrm{MEM}_{10}$ (mock infection) was intraperitoneally injected into 300 and 70 fish, respectively. Seven days after IPNV injection, 200 of the IPNV-injected fish were intraperitoneally challenged with IHNV at a dose of $10^{5.0}$ TCID $_{50} 50 \mu^{-1}$ fish $^{-1}$ (IPNV-IHNV group), and the remaining 100 fish were mock challenged with $\mathrm{MEM}_{10}$ (IPNV-Mock group). Fifty out of the 70 fish injected with $\mathrm{MEM}_{10}$ (mock infection) were divided into 2 groups, and were 

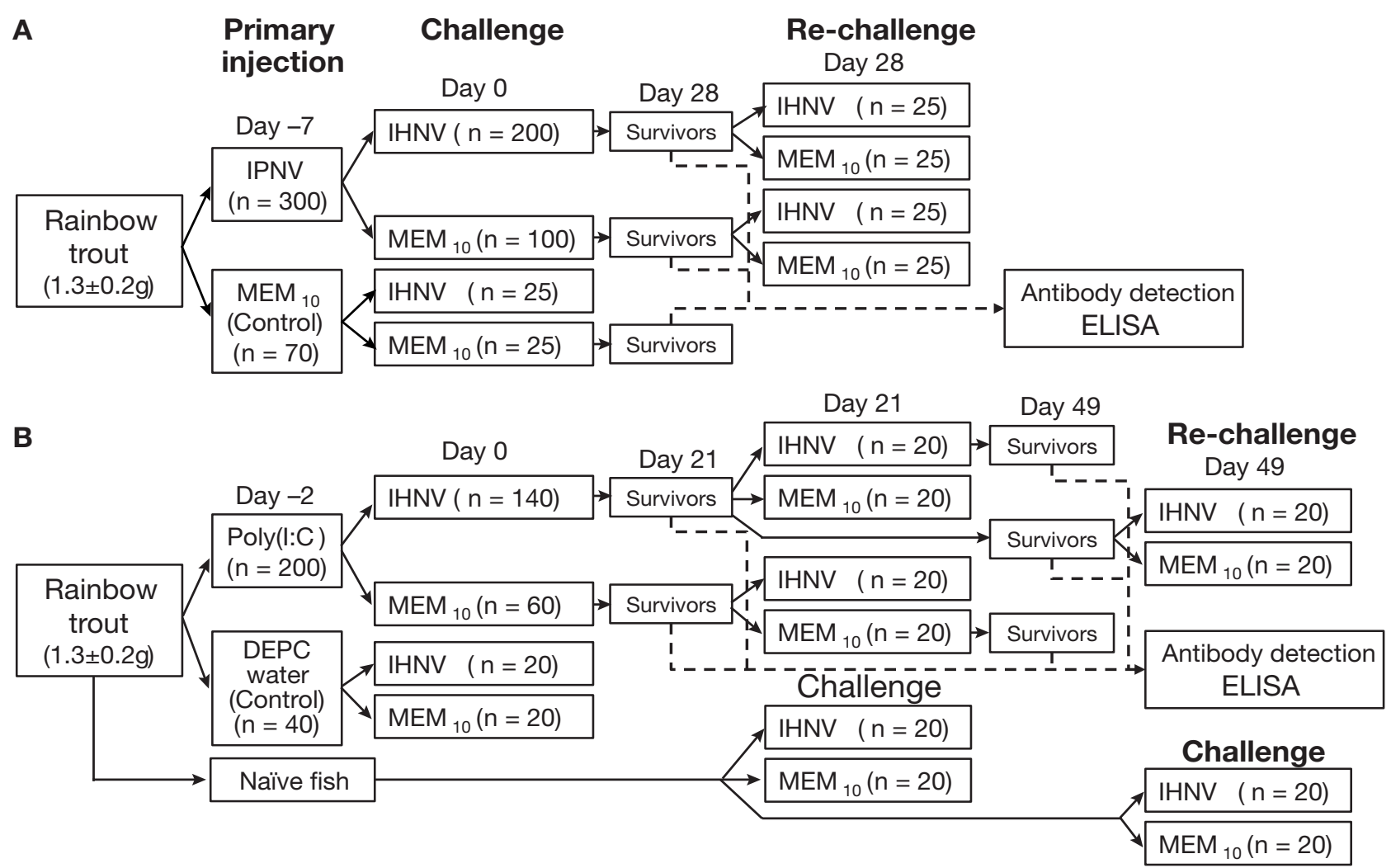

Fig. 1. Experimental design scheme of infectious pancreatic necrosis virus (IPNV)-infection, polyinosinic polycytidylic acid (Poly(I:C))-injection, infectious hematopoietic necrosis virus (IHNV) challenges and collection of fish sera for antibody detection via ELISA. (A) Scheme for IPNV protection; (B) scheme for Poly (I:C) protection. MEM 10 : supplemented minimum essential medium; DEPC: diethyl pyrocarbonate. Dashed lines: collection of fish sera from survivors for the antibody ELISA

intraperitoneally challenged with IHNV at a dose of $10^{5.0}$ TCID $_{50} 50 \mathrm{\mu l}^{-1}$ fish $^{-1}$ (Mock-IHNV group) or $\mathrm{MEM}_{10}$ (Mock-Mock group). Fish mortality was monitored daily for an additional $28 \mathrm{~d}$, and the relative percentage survival (RPS) was calculated at the end of the experiment according to the method of Amend (1981).

At the end of the experiment, sera were collected from 10 or 20 surviving fish out of each group, and subjected to IHNV-specific antibody detection ELISA, as described below (Fig. 1). Kidney tissues, obtained from 10 dead fish of the Mock-IHNV group and 5 survivors of each of the other groups, were homogenized with 9 volumes of Hanks' balanced salt solution (HBSS), and titrated in cell culture to determine the viral load in the tissue.

Re-challenge experiment with surviving fish from the primary IHNV challenge. On Day 28 after the primary IHNV challenge, 50 of the surviving fish from the IPNV-IHNV group were divided into 2 groups, and were intraperitoneally re-challenged with IHNV at a dose of $10^{5.0}$ TCID $_{50} 50 \mu^{-1}$ fish $^{-1}$ (IPNV-IHNV-IHNV group) or $\mathrm{MEM}_{10}$ (IPNV-IHNV-Mock) (Fig. 1). In the same manner, 50 survivors of the IPNV-Mock group were challenged with IHNV (IPNV-Mock-IHNV group) or $\mathrm{MEM}_{10}$ (IPNV-Mock-Mock group). Mortality was monitored daily for an additional $28 \mathrm{~d}$, and the RPS was calculated.

IHNV challenge for fish pre-injected with Poly(I:C). Poly(I:C) (Sigma) was dissolved in diethyl pyrocarbonate (DEPC)-treated water (Nippon Gene) at $1 \mathrm{mg} \mathrm{ml}^{-1}$ before using for each experiment. As shown in Fig. 1, a total of 200 fish were intraperitoneally injected with Poly(I:C) at $50 \mu \mathrm{g} 50 \mathrm{\mu l}^{-1} \mathrm{fish}^{-1}$, while the control group (40 fish) were injected with the same volume of DEPC water. Two days after Poly(I:C)-injection, 140 fish with Poly(I:C)-injection were challenged with IHNV at a dose of $10^{5.0}$ TCID $_{50} 50 \mu l^{-1}$ fish $^{-1}$ (Poly(I:C)-IHNV group), and the remaining 60 fish with Poly(I:C)-injection were mock challenged with $\mathrm{MEM}_{10}$ (Poly(I:C)Mock group). At the same time, fish of the control group without Poly(I:C)-injection were challenged with either IHNV or $\mathrm{MEM}_{10}$ in the same manner (Mock-IHNV and Mock-Mock groups, respectively). Mortality was monitored daily for an additional $21 \mathrm{~d}$. At the end of the experiment, sera and kidneys were collected from a few survivors of each group for IHNVspecific antibody detection ELISA and titration of viral infectivity, respectively. 
Re-challenge experiment with Poly(I:C)-injected fish surviving IHNV challenge. At $21 \mathrm{~d}$ after the primary IHNV challenge, 20 survivors in each of the Poly(I:C)-IHNV and Poly(I:C)-Mock groups were intraperitoneally re-challenged with IHNV at a dose of $10^{5.0}$ TCID $_{50} 50 \mathrm{\mu l}^{-1}$ fish $^{-1}$ (Poly(I:C)-IHNV-IHNV and Poly(I:C)-Mock-IHNV groups, respectively), and mock challenged with $\mathrm{MEM}_{10}$ (Poly(I:C)-IHNV-Mock and Poly(I:C)-Mock-Mock groups, respectively). In the same manner, $49 \mathrm{~d}$ after the primary IHNV challenge, 20 survivors in the Poly(I:C)-IHNV group were re-challenged with IHNV, and mock challenged with $\mathrm{MEM}_{10}$ respectively As additional positive and negative controls, 20 naïve fish, which had not been handled previously, were also challenged with IHNV or $\mathrm{MEM}_{10}$ (Naïve-IHNV and Naïve-Mock groups, respectively). Mortality was monitored daily for a further $21 \mathrm{~d}$ after the re-challenge with IHNV. At the end of the experiment, sera and kidneys were collected from 10 survivors of each group for IHNV-specific antibody detection ELISA and for titration of viral infectivity, respectively.

ELISA for detection of IHNV-specific antibodies from fish sera. Ca. 5 to $10 \mu \mathrm{l}$ of blood collected from caudal venous puncture, from survivors, was clotted at $4^{\circ} \mathrm{C}$ for $16 \mathrm{~h}$, and centrifuged at $12000 \times g$ for $10 \mathrm{~min}$ at $4^{\circ} \mathrm{C}$. The obtained fish sera were stored at $-20^{\circ} \mathrm{C}$ until use. Detection of IHNV-specific antibodies by ELISA was performed according to the method of Kim et al. (2007a, 2008). After clarification by centrifugation $\left(19000 \times g, 30 \mathrm{~min}, 4^{\circ} \mathrm{C}\right)$, supernatants of IHNV (target antigens) and VHSV (control antigens) containing a dose of approximately $10^{8.0} \mathrm{TCID}_{50} \mathrm{ml}^{-1}$ were diluted 10-fold with phosphate buffered saline (PBS), placed into ELISA plate wells at $50 \mu \mathrm{l}$ well $^{-1}$ and incubated at $4{ }^{\circ} \mathrm{C}$ overnight. ELISA wells were washed 3 times with PBS containing $0.05 \%$ Tween 20 (T-PBS), and blocked with 5\% skim milk in PBS at $25^{\circ} \mathrm{C}$ for $1 \mathrm{~h}$. The ELISA wells were washed 3 times with T-PBS, and then incubated with $50 \mu$ l of fish sera (primary) diluted $1: 40$ in $5 \%$ skim milk at $25^{\circ} \mathrm{C}$ for $1 \mathrm{~h}$. Plates were then incubated at $25^{\circ} \mathrm{C}$ for $30 \mathrm{~min}$ with rabbit (secondary) antiserum specific for rainbow trout IgM and anti-rabbit IgG swine Ig (tertiary) conjugated with horseradish peroxidase (Dako). Before use, both rabbit and swine sera were diluted $1: 1000$ in $5 \%$ skim milk. After washing 3 times with T-PBS, $50 \mu \mathrm{l}$ of substrate solution $\left(1 \mathrm{mg} \mathrm{ml}^{-1}\right.$ o-phenylenediamine, $\quad 0.03 \% \quad \mathrm{H}_{2} \mathrm{O}_{2}, \quad 100 \mathrm{mM} \quad \mathrm{Na}_{2} \mathrm{HPO}_{4}$, $50 \mathrm{mM}$ citric acid) was added to each well and incubated at $25^{\circ} \mathrm{C}$ for $30 \mathrm{~min}$. The reaction was stopped with $2 \mathrm{~N} \mathrm{H}_{2} \mathrm{SO}_{4}$, and then the optical density at $492 \mathrm{~nm}\left(\mathrm{OD}_{492}\right)$ was read using a microplate reader (MTP-300, Corona), and the OD values for IHNV-specific antibodies were corrected according to Kim et al.
(2008). The ELISA values among challenged groups were statistically analyzed using the Steel-Dwass test with a significance level of $5 \%$.

\section{RESULTS}

\section{Protection of rainbow trout pre-infected with IPNV against IHNV infection}

Rainbow trout, pre-infected with IPNV or mockinfected, were challenged $7 \mathrm{~d}$ later with IHNV (Fig. 2A). Infectivity titers of IPNV in kidney of the fish pre-infected with IPNV were between $10^{3.3}$ and $10^{4.8}$ TCID $_{50} \mathrm{~g}^{-1}$ tissue $3 \mathrm{~d}$ after the IPNV injection, but decreased below detection limit $\left(<10^{2.8}\right)$ to $10^{3.8} \mathrm{TCID}_{50}$ $\mathrm{g}^{-1}$ tissue at the time of IHNV challenge, i.e. at $7 \mathrm{~d}$ after the IPNV injection (data not shown). The fish preinfected with IPNV (IPNV-IHNV group) began to die $5 \mathrm{~d}$ after the IHNV challenge, but the survival rate was $68.8 \%$ at the end of the experiment. The fish without pre-infection with IPNV (Mock-IHNV group) began to
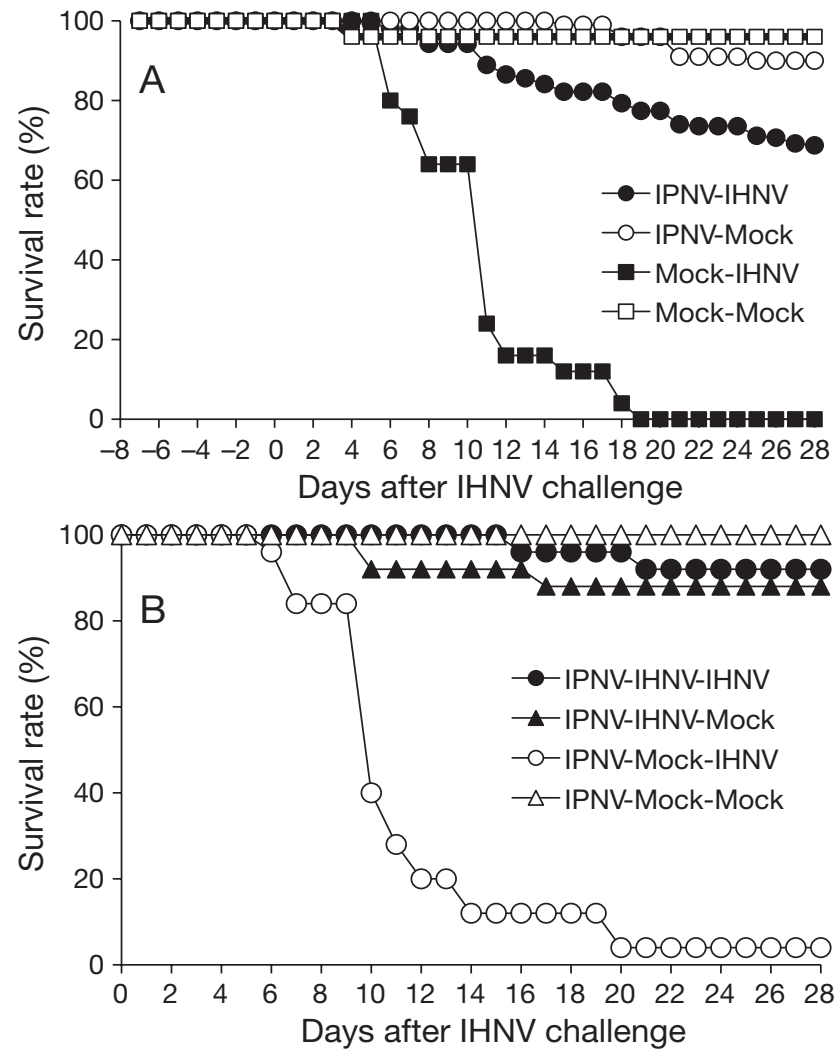

Fig. 2. Oncorhynchus mykiss. Survival rates following challenge with infectious hematopoietic necrosis virus (IHNV) in rainbow trout with and without pre-infection with non-lethal infectious pancreatic necrosis virus (IPNV). (A) Fish were challenged with IHNV $7 \mathrm{~d}$ after pre-infection with IPNV. (B) Surviving fish from IHNV and mock challenges following pre-infection with IPNV were re-challenged with IHNV 
die $4 \mathrm{~d}$ after the IHNV challenge, and all died within $19 \mathrm{~d}(0 \%$ survival rate). The RPS value of the IPNVIHNV group versus Mock-IHNV group was 68.8\%. The survival rates of fish in the IPNV-Mock and MockMock groups were 90.0 and $96.0 \%$, respectively. At the end of the experiment, neither IPNV nor IHNV was detected among survivors of IPNV-IHNV, IPNV-Mock and Mock-Mock groups, while IHNV at doses of $10^{5.1}$ to $10^{6.1} \mathrm{TCID}_{50} \mathrm{~g}^{-1}$ tissue was detected in kidneys of dead fish in the Mock-IHNV group. These results demonstrate that fish pre-infected with IPNV were highly protected from IHNV-infection in comparison with non-pre-infected fish.

The survivors of the IPNV-IHNV and IPNV-Mock groups were re-challenged with IHNV $28 \mathrm{~d}$ after the primary IHNV challenge (Fig. 2B). Fish in the IPNV-MockIHNV group began to die $6 \mathrm{~d}$ after the re-challenge with $I H N V$, and the final survival rate was $4 \%$. In contrast, final survival rate of the other 3 groups, IPNV-IHNVIHNV, IPNV-IHNV-Mock and IPNV-Mock-Mock, were $92.0,88.0$ and $100 \%$, respectively. Thus, the RPS value of the IPNV-IHNV-IHNV group versus the IPNVMock-IHNV group was $91.6 \%$. These results demonstrate that protection from IHNV challenge was observed in fish, which survived dual infection with IHNV and IPNV, but not in those which survived single infection with IPNV. Fish surviving from the dual infection remained alive throughout the experiment.

\section{Detection of IHNV-specific antibodies in fish that survived IPNV and IHNV infection}

Before the secondary IHNV challenge $(28 \mathrm{~d}$ after the primary IHNV challenge), sera were collected

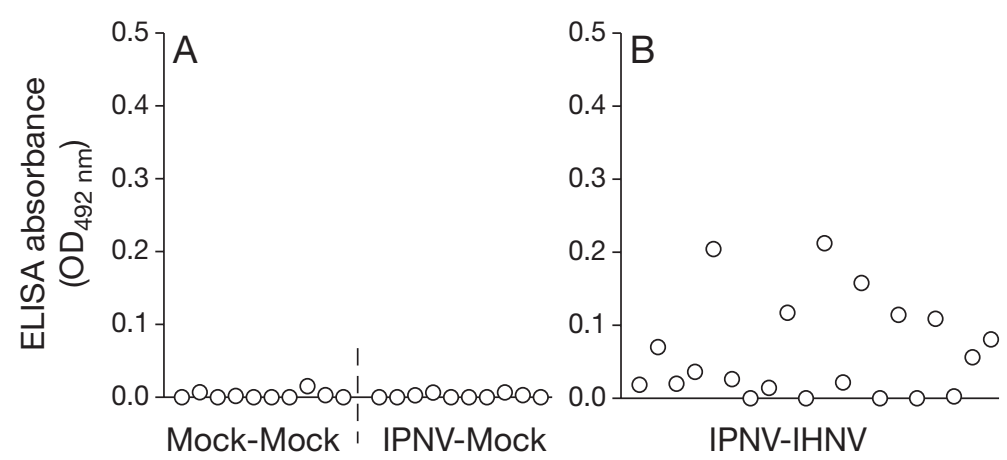

Fig. 3. Oncorhynchus mykiss. Detection of infectious hematopoietic necrosis virus (IHNV)-specific antibodies in sera of the surviving fish from infectious pancreatic necrosis virus (IPNV) and IHNV infection. Sera were collected $28 \mathrm{~d}$ after IHNV challenge. (A) Mock challenge; (B) IHNV challenge. Mock-Mock: sera from fish with neither IPNV-infection nor IHNV-infection; IPNV-Mock: sera from fish with mock challenge following pre-infection with IPNV; IPNV-IHNV: sera from the fish with IHNV challenge following pre-infection withIPNV. OD $_{492}$ : optical density at $492 \mathrm{~nm}$ from some of the surviving fish in the Mock-Mock, IPNV-Mock and IPNV-IHNV groups for detection of IHNV-specific antibodies (Fig. 3). ELISA absorbance $\left(\mathrm{OD}_{492}\right)$ of sera collected from the fish in the IPNVIHNV group ranged from 0 to 0.21 (Fig. 3B), while absorbance values from fish in the Mock-Mock and IPNV-Mock groups were all less than 0.02 (Fig. 3A), i.e. a significant difference was observed in the ELISA values for IHNV antigens between sera of the IPNV-IHNV and those of the IPNV-Mock group or Mock-Mock group $(\mathrm{p}<0.05)$. These results demonstrate that antibodies against IHNV antigens were produced in a large proportion of the surviving fish of IPNV-IHNV group during the primary IHNV challenge.

\section{Protection of rainbow trout injected with Poly(I:C) against IHNV infection}

Rainbow trout injected with or without Poly(I:C) were challenged $2 \mathrm{~d}$ later with IHNV, and mortalities were monitored (Fig. 4). Fish pre-injected with Poly(I:C) (Poly(I:C)-IHNV group) showed 95.7\% survival rate, which was clearly higher than that of fish pre-injected with DEPC water (Control group). RPS of the Poly(I:C)-IHNV group versus the Control-IHNV group was $95.2 \%$. No infectivity of IHNV was detected in kidneys of the survivors in the Poly(I:C)IHNV group, although doses of $10^{7.1}$ to $10^{7.6} \mathrm{TCID}_{50}$ $\mathrm{g}^{-1}$ tissue of IHNV were detected in dead fish collected 6 to $18 \mathrm{~d}$ after the challenge in the ControlIHNV group (data not shown). No mortality was observed in fish of the Poly(I:C)-Mock and ControlMock groups (Fig. 4A), and no IHNV was detected (data not shown).

Mortalities in surviving fish of the Poly(I:C)-IHNV and Poly(I:C)-Mock groups after re-challenge with IHNV $21 \mathrm{~d}$ after the primary IHNV challenge were shown in Fig. 4B. No mortality was observed in the Poly(I:C)IHNV-IHNV group after re-challenge with IHNV (final survival rate: $100 \%$ ). Seven days after IHNV challenge in the Poly(I:C)-MockIHNV(re-challenge) and Naïve-IHNV (initial challenge) groups, fish began to die, and the final survival rate of each group was $10 \%$. RPS of the Poly(I:C)-IHNV-IHNV group versus Poly(I:C)-Mock-IHNV or Naïve-IHNV groups were both $100 \%$. Only one fish of the Poly(I:C)-IHNV-Mock group died $9 \mathrm{~d}$ after the re-challenge with IHNV (final survival rate: $95 \%$ ), while no mortality was observed in the Poly(I:C)-Mock-Mock and Naïve-Mock groups. 

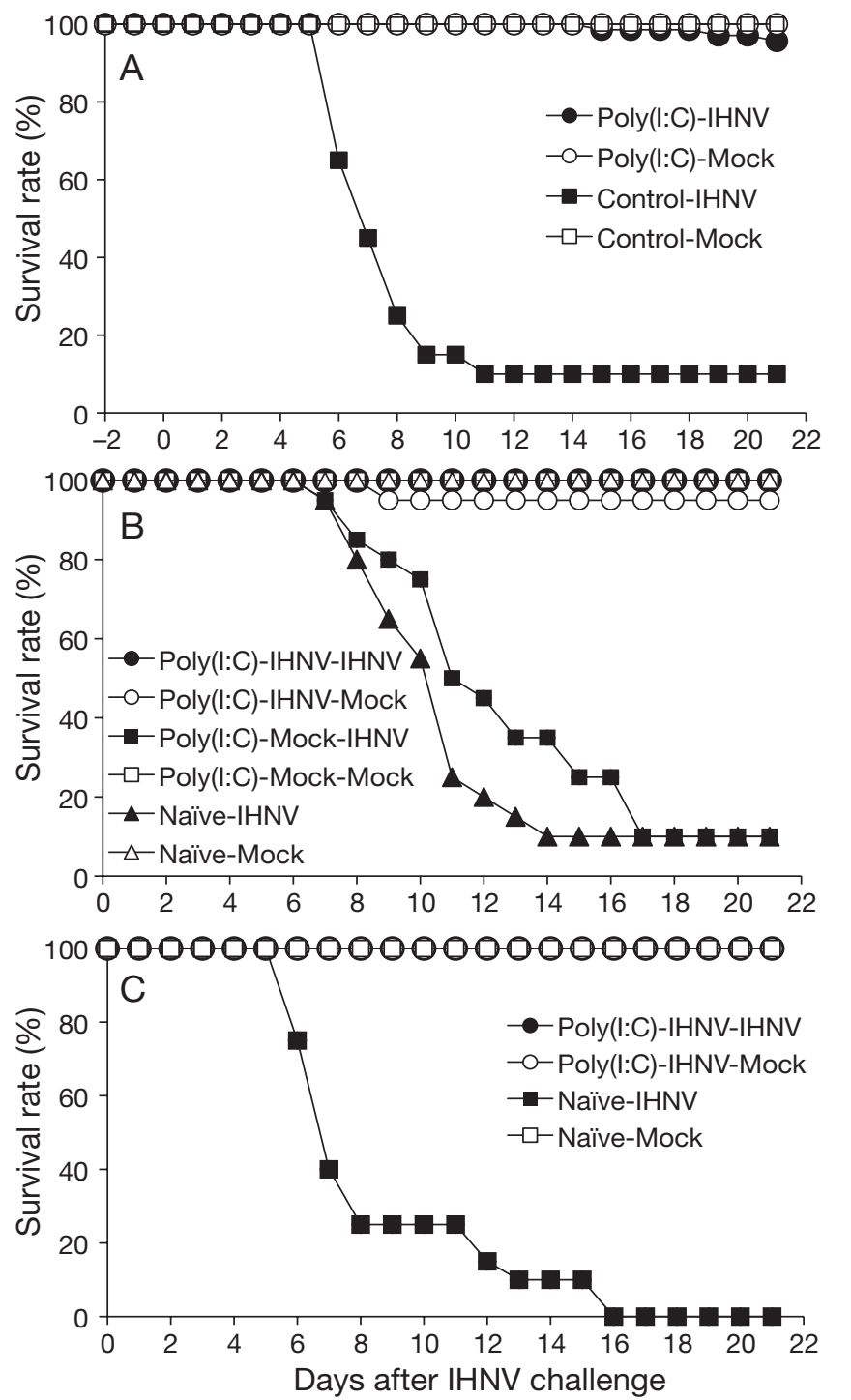

Fig. 4. Oncorhynchus mykiss. Survival rates following challenge with infectious hematopoietic necrosis virus (IHNV) in rainbow trout with and without polyinosinic polycytidylic (Poly(I:C)) pre-injection. (A) Fish were challenged with IHNV $2 \mathrm{~d}$ after pre-injection with Poly(I:C). (B) Surviving fish from IHNV and mock challenges following pre-injection with Poly(I:C) were re-challenged with IHNV $21 \mathrm{~d}$ after the primary IHNV challenge. (C) Further challenge with IHNV $49 \mathrm{~d}$ after the primary IHNV challenge

In a separate experiment, survivors of the Poly(I:C)IHNV and Poly(I:C)-Mock groups, as well as the fish in the Naïve-IHNV group, were also challenged with IHNV $49 \mathrm{~d}$ after the primary IHNV challenge (Fig. 4C). All fish in the Naïve-IHNV group died within $16 \mathrm{~d}$ after the challenge with IHNV, while no mortality was observed in Poly(I:C)-IHNV-IHNV, Poly(I:C)-IHNVMock and Naïve-Mock groups. RPS of the Poly(I:C)IHNV-IHNV group versus Naïve-IHNV group was $100 \%$.

\section{Detection of IHNV-specific antibodies in fish that survived IHNV challenge following Poly(I:C)- injection}

ELISA absorbance values of sera obtained from Poly(I:C)-injected survivors of the IHNV challenges are shown in Fig. 5. Firstly, sera were collected from survivors in the Poly(I:C)-Mock and Poly(I:C)-IHNV groups $21 \mathrm{~d}$ after the primary IHNV challenge, i.e. before the secondary IHNV challenge. Sera from the Poly(I:C)-Mock group showed ELISA values of $<0.02$, and those from the Poly(I:C)-IHNV group showed ELISA values ranging from 0 to 0.03 (Fig. 5A). The ELISA values of sera from the Poly(I:C)-IHNV group seemed to be slightly higher than those from the Poly(I:C)-Mock group although no statistical difference $(p<0.05)$ was observed between them, suggesting that the ELISA values from the Poly(I:C)-IHNV group were not sufficiently positive for IHNV-specific antibodies.

Secondly, sera were collected from survivors in the Poly(I:C)-Mock-Mock, Poly(I:C)-IHNV-Mock and Poly(I:C)-IHNV-IHNV groups $49 \mathrm{~d}$ after the primary IHNV challenge, i.e. $28 \mathrm{~d}$ after the secondary IHNV challenge (Fig. 5B). ELISA values of sera from Poly(I:C)Mock-Mock group were all less than 0.01, and those from Poly(I:C)-IHNV-Mock and Poly(I:C)-IHNV-IHNV groups ranged from 0.0 to 0.80 (average: 0.15 ) and from 0.06 to 0.58 (average: 0.24), respectively (Fig. 5B). Statistical differences $(\mathrm{p}<0.05)$ were observed in the ELISA values between the Poly(I:C)-Mock-Mock and Poly(I:C)-IHNV-Mock or Poly(I:C)-IHNV-IHNV groups, but not between the Poly(I:C)-IHNV-Mock and Poly(I:C)-IHNV-IHNV groups. These results demonstrate that IHNV-specific antibodies were produced in those fish with Poly(I:C)-injection by IHNV challenge between 21 and $49 \mathrm{~d}$ after the challenge. From the present data, it was unfortunately difficult to confirm that the level of IHNV-specific antibodies was enhanced by the secondary IHNV challenge.

\section{DISCUSSION}

Rainbow trout pre-infected with IPNV were highly protected from IHNV infection, as the survival rate in the Mock-IHNV group was zero, but $68.8 \%$ in the IPNV-IHNV group (Fig. 2A). It was reported recently that protection from IHNV infection induced by preexposure to IPNV (de Kinkelin et al. 1992, Byrne et al. 2008) was due to induction of IFN activity by the pre-infection with IPNV (McBeath et al. 2007, Byrne et al. 2008). Thus, the protection from the IHNV challenge observed in the IPNV-IHNV group could likewise be due to induction of IFN activity by pre-infection with IPNV, although expression of $M x$ gene, an 

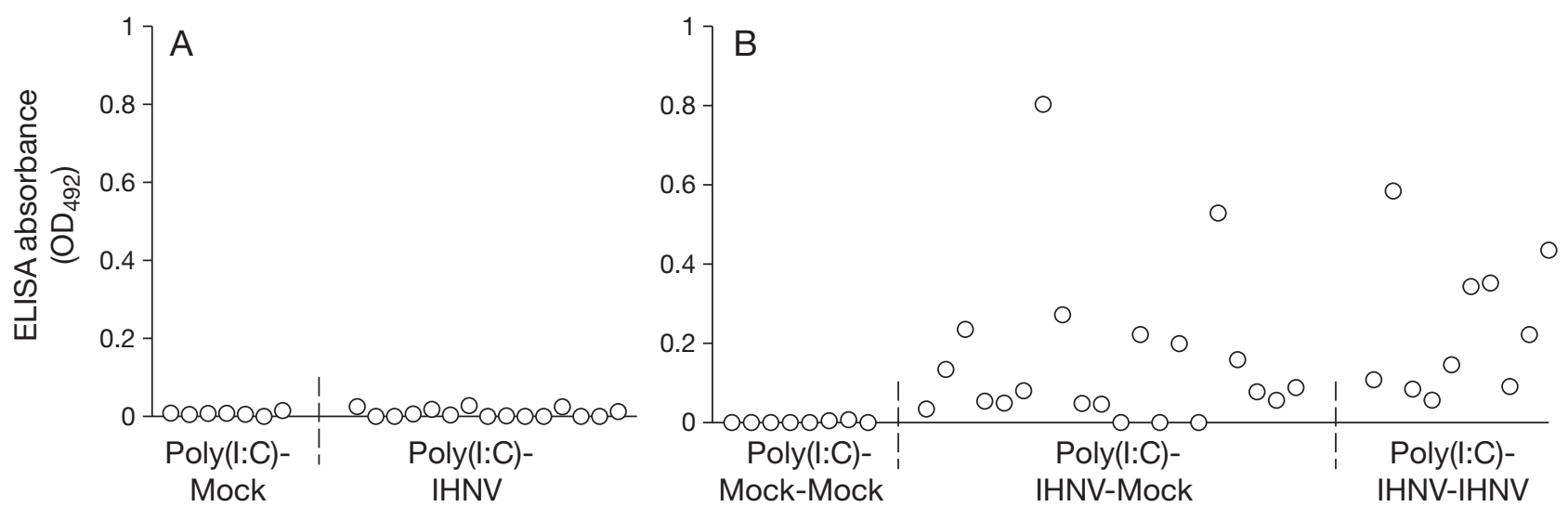

Fig. 5. Oncorhynchus mykiss. Detection of infectious hematopoietic necrosis virus (IHNV)-specific antibodies from sera of the surviving fish from IHNV challenge following pre-injection with polyinosinic polycytidylic acid (Poly(I:C)). Sera were collected (A) $21 \mathrm{~d}$, (B) $49 \mathrm{~d}$ after the primary IHNV challenge. Poly(I:C)-Mock: fish with Poly(I:C)-injection and mock challenge; Poly(I:C)IHNV: with Poly(I:C)-injection and IHNV challenge; Poly(I:C)-IHNV-IHNV: with Poly(I:C)-injection and 2 subsequent IHNV challenges. $\mathrm{OD}_{492}$ : optical density at $492 \mathrm{~nm}$

indicator for IFN induction, was not confirmed in the present study.

By antibody detection ELISA, it was confirmed that IHNV-specific antibodies were produced in the surviving fish from the IHNV challenge following IPNV preinfection (IPNV-IHNV group) (Fig. 3B). Moreover, it was demonstrated that those survivors were highly protected from re-challenge with IHNV (IPNV-IHNV-IHNV group, Fig. 2B), suggesting that fish immunity against IHNV was established in the survivors of the IPNVIHNV group. These phenomena could be explained as follows: through induction of IFN by primary infection with non-lethal IPNV, fish developed an antiviral state, which allowed the fish to survive the secondary infection with IHNV and thus to acquire IHNV-specific immunity. Thus, we speculate that immunization against a pathogenic virus can be established by intentional infection with the live pathogenic virus during the phase of IFN induction by pre-infection with a non-lethal virus.

Poly(I:C), a synthetic double-stranded RNA, is well known as an inducer of IFNs in many different fish models (Eaton 1990, Jensen \& Robertsen 2002, Jensen et al. 2002, Plant et al. 2005, Fernandez-Trujillo et al. 2008). In the present study, Poly(I:C) was evaluated as a substitute for a non-lethal IPNV to induce the antiviral state in rainbow trout (Fig. 4A). The fish preinjected with Poly(I:C) were highly protected from IHNV challenge, as the survival rate of the controlIHNV group was only $10 \%$, while the survival rate of the Poly(I:C)-IHNV group was 95.7\% (RPS: 95.2\%, Fig. 4A). Moreover, no infectious IHNV was detected among the survivors of the Poly(I:C)-IHNV group. Thus, it can be confirmed that an antiviral state was induced in the fish of Poly(I:C)-IHNV group by preinjection with Poly(I:C) 2 d prior to IHNV challenge, so Poly(I:C) could be useful as a substitute for non-lethal viruses. However, the antiviral state induced by Poly(I:C)-injection completely disappeared within a short period, as the surviving fish of the Poly(I:C)Mock group showed only $10 \%$ survival rate (RPS: 0\%) after the IHNV challenge 21 d later after the Poly(I:C)injection (Fig. 4B). These results agreed with previous data where $\mathrm{Mx}$ gene responses against Poly(I:C) peaked $1 \mathrm{~d}$ after the Poly(I:C)-injection in rainbow trout and Atlantic salmon, and subsequently disappeared within 15 d (Lockhart et al. 2004, Purcell et al. 2004). Similarly, the antiviral state against fish nodavirus induced by Poly(I:C)-injection lasted for a few days after injection in sevenband grouper Epinephelus septemfasciatus and subsequently decreased (Nishizawa et al. 2009, this issue).

The surviving fish of the Poly(I:C)-IHNV group showed $100 \%$ survival rate (RPS: 100\%) against the re-challenge with IHNV $21 \mathrm{~d}$ after the primary challenge (Fig. 4B). However, the sera collected from those survivors had no detectable IHNV-specific antibody, and no clear difference was observed in ELISA values of sera between Poly(I:C)-IHNV and Poly(I:C)-Mock groups (Fig. 5A). Sera collected from the Poly(I:C)IHNV-Mock group $49 \mathrm{~d}$ after the primary IHNV challenge were positive for IHNV-specific antibodies, because ELISA values of these sera were clearly higher than those from the Poly(I:C)-Mock-Mock group (negative control), but the same level as those from the surviving fish with re-challenge of IHNV (Poly(I:C)-IHNV-IHNV group) (Fig. 5B). It was noted that antibody levels in fish sera of the Poly(I:C)-IHNVMock group were the same as those of the Poly(I:C)IHNV group, and thus it was considered that the IHNV-specific antibody level in sera from the Poly(I:C)-IHNV group increased $21 \mathrm{~d}$ after the primary IHNV challenge. Therefore, it is suggested that the 
surviving fish of the Poly(I:C)-IHNV group could have already acquired IHNV-immunity at $21 \mathrm{~d}$ after the primary challenge even though IHNV-specific antibodies were still under the detection limit of the present ELISA system. Moreover, it can be considered that the IHNV-immunity acquired in fish could last a long time, because the surviving fish in the Poly(I:C)-IHNV groups showed no mortality (RPS: $100 \%$ ) after the re-challenge with IHNV $49 \mathrm{~d}$ after the primary challenge (Fig. 4C). As mentioned above, duration of the antiviral state induced in fish by Poly(I:C)-injection lasted only a few days after the Poly(I:C)-injection, so IHNV should be injected into fish within the antiviral state for establishment of IHNV-immunity in fish.

In conclusion, the present study demonstrated that IHNV-specific immunity was established in rainbow trout by intentional infection with IHNV during the phase of antiviral state by preceding infection with nonlethal IPNV. Moreover, Poly(I:C) could be used as a substitute for non-lethal IPNV. Although several efficacious vaccines for fish viruses have been developed, such as killed, attenuated, subunit, recombinant and DNA vaccines (Xu et al. 1991, Anderson et al. 1996, Winton 1997, Cain et al. 1999, Kim et al. 2000, Lorenzen et al. 2002, Biering et al. 2005), the present method with IHNV challenge following pre-injection with non-lethal IPNV or Poly(I:C) is a novel immunization method for inducing protection against IHNV. It uses pre-infection with a non-lethal dose of IPNV, or injection with Poly(I:C), to stimulate a transient, non-specific anti-viral state that allows the fish to survive an IHNV infection that would otherwise be lethal. In our preliminary experiments, usefulness of the present method was also confirmed for protection of sevenband grouper against fish nodavirus, a causative agent of viral nervous necrosis (Nishizawa et al. 2009), and in Japanese flounder against viral hemorrhagic septicemia virus (VHSV) (I. Takami, T. Nishizawa \& M. Yoshimizu unpubl.). Thus, we expect that the present method can be applied to various other viruses in other fish species, including non-culturable and non-identified viruses. However, more detailed experiments are required before application of the present method to open aquaculture, since some risks remain e.g. re-induction of the live virus used for immunization under stress conditions such as spawning maturation of the fish, and the spread of the virus used for immunization beyond the target.

Acknowledgements. The authors gratefully acknowledge Mr. Katuhiro Umeda of National Research Institute of Aquaculture for maintenance of fish rearing. The SPF-rainbow trout juveniles were kindly provided by Mr. Masakazu Kohara of Nagano Prefectural Fisheries Experimental Station. This study was partially supported by a Grant-in-Aid for Scientific Research (B) from the Ministry of Education, Culture, Sports, Science and Technology of Japan.

\section{LITERATURE CITED}

Amend DF (1981) Potency testing of fish vaccines. Dev Biol Stand 49:447-454

Anderson ED, Mourich DV, Fahrenkrug SC, LaPatra S, Shepherd J, Leong JC (1996) Genetic immunization of rainbow trout (Oncorhynchus mykiss) against infectious hematopoietic necrosis virus. Mol Mar Biol Biotechnol 5: $114-122$

Biering E, Villoing S, Sommerset I, Christie KE (2005) Update on viral vaccines for fish. In: Midtlying PJ (ed) Progress in fish vaccinology. Developments in biologicals, Vol 121. Karger, Basel, p 97-113

Byrne N, Castric J, Lamour F, Cabon J, Quentel C (2008) Study of the viral interference between infectious pancreatic necrosis virus (IPNV) and infectious haematopoietic necrosis virus (IHNV) in rainbow trout (Oncorhynchus mykiss). Fish Shellfish Immunol 24:489-497

Cain KD, Byrne KM, Brassfield AL, LaPatra SE, Ristow SS (1999) Temperature dependent characteristics of a recombinant infectious hematopoietic necrosis virus glycoprotein produced in insect cells. Dis Aquat Org 36:1-10

Das BK, Collet B, Snow M, Ellis AE (2007) Expression kinetics of ISG15 and viral major capsid protein (VP2) in Atlantic cod (Gadus morhua L.) fry following infection with infectious pancreatic necrosis virus (IPNV). Fish Shellfish Immunol 23:825-830

de Kinkelin P, Dorson M, Renault T (1992) Interferon and viral interference in viruses of salomnid fish. In: Kimura T (ed) Proceedings of the OJI international symposium on salmonid diseases. Hokkaido University Press, Sapporo, p 241-249

Eaton WD (1990) Anti-viral activity in four species of salmonids following exposure to poly inosinic:cytidylic acid. Dis Aquat Org 9:193-198

Fernandez-Trujillo A, Ferro P, Garcia-Rosado E, Infante C and others (2008) Poly I:C induces Mx transcription and promotes an antiviral state against sole aquabirnavirus in the flatfish Senegalese sole (Solea senegalensis Kaup). Fish Shellfish Immunol 24:279-285

> Hedrick RP, La Patra SE, Yun S, Lauda KA, Jones GR, Congleton JL, de Kinkelin P (1994) Induction of protection from infectious hematopoietic necrosis virus in rainbow trout Oncorhynchus mykiss by pre-exposure to the avirulent cutthroat trout virus (CTV). Dis Aquat Org 20:111-118

Jensen I, Robertsen B (2002) Effect of double-stranded RNA and interferon on the antiviral activity of Atlantic salmon cells against infectious salmon anemia virus and infectious pancreatic necrosis virus. Fish Shellfish Immunol 13: 221-241

Jensen I, Albuquerque A, Sommer AI, Robertsen B (2002) Effect of poly I:C on the expression of Mx proteins and resistance against infection by infectious salmon anaemia virus in Atlantic salmon. Fish Shellfish Immunol 13: $311-326$

> Johansen LH, Sommer AI (2001) Infectious pancreatic necrosis virus infection in Atlantic salmon Salmo salar postsmolts affects the outcome of secondary infections with infectious salmon anaemia virus or Vibrio salmonicida. Dis Aquat Org 47:109-117

> Kim CH, Johnson MC, Drennan JD, Simon BE, Thomann E, Leong JC (2000) DNA vaccines encoding viral glycoproteins induce nonspecific immunity and Mx protein synthesis in fish. J Virol 74:7048-7054

> Kim WS, Nishizawa T, Yoshimizu M (2007a) Non-specific adsorption of fish immunoglobulin $\mathrm{M}$ (IgM) to blocking 
reagents on ELISA plate wells. Dis Aquat Org 78:55-59

Kim WS, Oh MJ, Nishizawa T, Park JW, Kurath G, Yoshimizu M (2007b) Genotyping of Korean isolates of infectious hematopoietic necrosis virus (IHNV) based on the glycoprotein gene. Arch Virol 152:2119-2124

Kim WS, Mochizuki M, Nishizawa T, Yoshimizu M (2008) Detection of specific antibodies against infectious hematopoietic necrosis virus (IHNV) from rainbow trout sera using ELISA with 2 novirhabdoviruses. Fish Pathol 43:112-116

Kimura T, Yoshimizu M (1991) Viral diseases of fish in Japan. Annu Rev Fish Dis 1:67-82

Kurath G, Ahern KG, Pearson GD, Leong JC (1985) Molecular cloning of the six mRNA species of infectious hematopoietic necrosis virus, a fish rhabdovirus, and gene order determination by R-loop mapping. J Virol 53:469-476

LaPatra SE, Lauda KA, Jones GR (1995) Aquareovirus interference mediated resistance to infectious hematopoietic necrosis virus. Vet Res 26:455-459

Lockhart K, Gahlawat SK, Soto-Mosquera D, Bowden TJ, Ellis AE (2004) IPNV carrier Atlantic salmon growers do not express Mx mRNA and poly I:C-induced Mx response dose not cure the carrier state. Fish Shellfish Immunol 17: $347-352$

Lorenzen N, Lorenzen E, Einer-Jensen K, LaPatra SE (2002) Immunity induced shortly after DNA vaccination of rainbow trout against rhabdoviruses protects against heterologous virus but not against bacterial pathogens. Dev Comp Immunol 26:173-179

McBeath AJ, Snow M, Secombes CJ, Ellis AE, Collet B (2007) Expression kinetics of interferon and interferon-induced genes in Atlantic salmon (Salmo salar) following infection with infectious pancreatic necrosis virus and infectious salmon anaemia virus. Fish Shellfish Immunol 22:230-241

Nishizawa $T$, Iida $H$, Takano $R$, Isshiki $T$, Nakajima $K$, Muroga K (2002) Genetic relatedness among Japanese, American and European isolates of viral hemorrhagic septicemia virus (VHSV) based on partial G and P genes. Dis Aquat Org 48:143-148

Nishizawa T, Kinoshita S, Yoshimizu M (2005) An approach for genogrouping of Japanese isolates of aquabirnaviruses in a new genogroup, VII, based on the VP2/NS junction region. J Gen Virol 86:1973-1978

Nishizawa T, Kinoshita S, Kim WS, Higashi S, Yoshimizu M (2006a) Nucleotide diversity of Japanese isolates of infectious hematopoietic necrosis virus (IHNV) based on the glycoprotein gene. Dis Aquat Org 71:267-272

Nishizawa T, Savaş H, Işidan $H$, Üstündağ $C$, Iwamoto $H$, Yoshimizu M (2006b) Genotyping and pathogenicity of viral hemorrhagic septicemia virus (VHSV) from free-living turbot Psetta maxima in Turkish coastal area of the Black Sea. Appl Environ Microbiol 72:2373-2378

Nishizawa T, Takami I, Kokawa Y, Yoshimizu M (2009) Fish immunization using a synthetic double-stranded RNA Poly(I:C), an interferon inducer, offers protection against RGNNV, a fish nodavirus. Dis Aquat Org 83:115-122

Pakingking R Jr, Takano R, Nishizawa T, Mori K, Iida Y, Arimoto M, Muroga K (2003) Experimental coinfection with aquabirnavirus and viral hemorrhagic septicemia virus (VHSV), Edwardsiella tarda or Streptococcus iniae in

Editorial responsibility: Mark Crane,

Geelong, Victoria, Australia
Japanese flounder Paralichthys olivaceus. Fish Pathol 38: $15-21$

Pakingking R Jr, Okinaka Y, Mori K, Arimoto M, Muroga K, Nakai T (2004) In vivo and in vitro analysis of the resistance against viral haemorrhagic septicaemia virus in Japanese flounder (Paralichthys olivaceus) precedingly infected with aquabirnavirus. Fish Shellfish Immunol 17: 1-11

Pakingking R Jr, Mori K, Sugaya T, Oka M, Okinaka Y, Nakai $\mathrm{T}$ (2005) Aquabirnavirus-induced protection of marine fish against piscine nodavirus infection. Fish Pathol 40: 125-131

> Plant KP, Harbottle H, Thune RL (2005) Poly I:C induces an antiviral state against Ictalurid Herpesvirus 1 and Mx1 transcription in the channel catfish (Ictalurus punctatus). Dev Comp Immunol 29:627-635

> Purcell MK, Kurath G, Garver KA, Herwig RP, Winton JR (2004) Quantitative expression profiling of immune response genes in rainbow trout following infectious haematopoietic necrosis virus (IHNV) infection or DNA vaccination. Fish Shellfish Immunol 17:447-462

Takano R, Nishizawa T, Arimoto M, Muroga K (2000) Isolation of viral haemorrhagic septicaemia virus (VHSV) from wild Japanes flounder Paralichthys olivaceus. Bull Eur Assoc Fish Pathol 20:186-192

Takano R, Mori K, Nishizawa T, Arimoto M, Muroga K (2001) Isolation of viruses from wild Japanese flounder Paralichthys olivaceus. Fish Pathol 36:153-160

Tordo N, Benmansour A, Calisher C, Dietzgen RG and others (2005) Family Rhabdoviridae. In: Fauquet CM, Mayo JA, Maniloff J, Desselberger D, Ball LA (eds) Virus taxonomy. Eighth report of the International Committee for Taxonomy of Viruses. Elsevier, New York, NY, p 623-653

Trobridge GD, Chious PP, Leong JC (1997) Cloning of the rainbow trout (Oncorhynchus mykiss) $\mathrm{Mx} 2$ and $\mathrm{Mx} 3$ cDNAs and characterization of trout Mx protein expression in salmon cells. J Virol 71:5304-5311

Winton JR (1991) Recent advances in detection and control of infectious hematopoietic necrosis virus in aquaculture. Annu Rev Fish Dis 1:83-93

Winton JR (1997) Immunization with viral antigens: infectious haematopoietic necrosis. In: Gudding R, Lillehaug A, Midtlyng PJ, Brown F (eds) Fish vaccinology, Vol 90. Developments in biological standardization. Karger, Basel, p 211-220

Wolf K (1988) Infectious hematopoietic necrosis. In: Wolf K (ed) Fish viruses and fish viral diseases. Cornell University Press, Ithaca, NY, p 83-114

Xu L, Mourich DV, Engelking HM, Ristow S, Arnzen J, Leong JC (1991) Epitope mapping and characterization of the infectious hematopoietic necrosis virus glycoprotein, using fusion proteins synthesized in Escherichia coli. J Virol 65:1611-1615

Yoshimizu M (1996) Disease problems of salmonid fish in Japan caused by international trade. Rev Sci Tech Off Int Epizoot 15:533-549

Yoshimizu M (2003) Control strategy for viral diseases of salmonids and flounder. In: Lee CS, O'Bryen PJ (eds) Biosecurity in aquaculture production systems: exclusion of pathogens and other undesirables. World Aquaculture Society, Baton Rouge, LA, p 35-41

Submitted: July 14, 2008; Accepted: October 28, 2008

Proofs received from author(s): February 6, 2009 